\title{
O MODERNISMO ANTROPOLÓGICO DE EDWARD SAPIR Entrevista com Richard Handler
}

Tradução de Luciana Villas Bôas

As ideias de Edward Sapir, ainda pouco incorporadas à antropologia produzida no Brasil, são o objeto desta entrevista gentilmente concedida a Sociologia \& Antropologia pelo professor Richard Handler. Professor do Departamento de Antropologia Cultural e Diretor do Programa de Estudos de Desenvolvimento Global da Universidade de Virgínia, nos Estados Unidos, Handler é um dos editores das obras completas de Edward Sapir, projeto editorial de 16 volumes intitulado The collected works of Edward Sapir e publicado pela Mouton de Gruyter. Além disso, mobilizou ideias centrais de Sapir na abordagem da política cultural e do movimento nacionalista em Québec, Canadá, em seu trabalho Nationalism and the politics of culture in Quebec, resultado de sua pesquisa de doutorado na Universidade de Chicago. Sapir é também um dos principais autores enfocados em seu livro mais recente Critics against culture: Anthropological observers of mass society (2005). O trabalho do professor Richard Handler vem, portanto, não apenas contribuindo para a renovação do interesse pela obra de Edward Sapir, ao lhe conferir visibilidade, como chamando a atenção para o caráter seminal de suas ideias no passado e para o seu potencial de interpelação aos debates em curso no presente.

Alemão emigrado para os Estados Unidos no final do século XIX, Sapir formou-se na Universidade de Columbia, doutorando-se em 1909 sob a orientação de Franz Boas, que lhe despertou o interesse para as línguas indígenas norte-americanas. Sapir foi pioneiro no estudo das relações entre a linguística e a antropologia, além de ter, posteriormente, liderado a reação contra a teoria da cultura como um "superorganismo" proposta por Alfred Kroeber, refutando o determinismo cultural nela pressuposto em favor da participação ativa dos indivíduos no processo cultural. No vasto corpus legado por Sapir nas áreas da linguística e da antropologia, destacam-se o ensaio Time perspective in aboriginal American culture: a study in method (1916) e Language: an introduction to the study of speech (1921), único livro que publicou em vida, e o artigo fundamental, republicado em nova tradução nesta edição de Sociologia \& Antropologia, "Culture, genuine and spurious" (1924). Essas e outras questões, tais como a inserção de 
Sapir no contexto da antropologia norte-americana e sua relação com o modernismo literário e artístico americano e a cultura alemã, ganham destaque nesta entrevista. Nela o leitor encontrará ainda indicações preciosas sobre as relações e particularidades da abordagem de Sapir em relação a seus contemporâneos, especialmente outros antropólogos boasianos, como Ruth Benedict, ou linguistas, como Saussure; e, acima de tudo, sobre sua consistente visão acerca da importância do indivíduo nas interações e da cultura como processo, atividade, não uma coisa. É o modo particular como elabora e trata a relação entre criatividade individual e padrões culturais que torna a obra de Sapir, paradoxalmente, ainda nossa contemporânea. Por tudo isso, a presente entrevista configura uma informal introdução ao pensamento de Sapir e um convite à leitura da sua própria obra. E nos artigos que se lhe seguem, o leitor encontrará mais estímulo e elementos nesse sentido. Boa leitura!

José Reginaldo Santos Gonçalves. Você é um dos editores de The collected works of Edward Sapir (junto com Regna Darnell, Judith Irvine e outros) [publicada em 1999 pela Mouton de Gruyter]. Você também escreveu artigos excelentes e úteis sobre Sapir e outros que pertencem à tradição de Franz Boas, como Ruth Benedict e Margaret Mead. Quando e como você veio a se interessar pelas obras de Sapir? E que importância tiveram as ideias de Sapir para o seu próprio trabalho enquanto antropólogo cultural?

Richard Handler. Em alguns autores o brilhantismo intelectual parece se expressar diretamente pela voz autoral. Durante a minha carreira, fiquei impressionado com três vozes intelectuais: Jane Austen, Edward Sapir e Erving Goffman. Li Jane Austen pela primeira vez quando estava no meu segundo ano de gradução, na Universidade de Columbia [em Nova York]. Naquele tempo, eu estava fazendo o meu primeiro curso de antropologia. Fiquei imediatamente impressionado com o brilhantismo do que eu era capaz de perceber na voz e no olhar etnográficos de Jane Austen. Fiz uma anotação para retornar a Jane Austen, antropologicamente, um projeto que eu só completaria bem mais tarde (Handler, 1976; Handler \& Segal 1990).

A primeira vez que li Sapir seriamente foi durante o curso de pósgraduação, na Universidade de Chicago, em um seminário em 1975 sobre antropologia norte-americana entre as duas Grandes Guerras, ministrado pelo grande George Stocking (Stocking, 1976). Stocking encarregou cada aluno de um antropólogo proeminente e a sorte quis que eu ficasse com Sapir. Eu logo fiquei impressionado, como ficara ao ler Jane Austen, com o brilhantismo da sua voz. Era como se estivesse falando diretamente comigo. E rapidamente vi que a abordagem de Sapir da teoria da cultura (veja mais a respeito abaixo) podia me ajudar a formular uma abordagem da política cultural do nacionalismo québécois que se tornaria o foco da minha pesquisa de doutorado. 
A primeira vez que li Goffman foi muito mais tarde na minha carreira, quando comecei a lecionar Stigma (Goffman, 1963) para alunos de graduação nos anos noventa. Mais uma vez, fui capturado pela voz e o brilhantismo intelectual que o texto transmitia. Goffman, como Sapir, era filho de imigrantes do Leste europeu para os Estados Unidos, e o trabalho de ambos tinha uma qualidade talmúdica. Anos atrás encontrei o filho de Sapir, David, que lecionou por muito tempo no nosso departamento em Virginia, e perguntou sobre o que eu estava trabalhando. Disse que estava escrevendo uma série de ensaios sobre Goffmann (Handler, 2009, 2012) e acrescentei, um pouco hesitante, que na minha opinião Goffman era um dos poucos cientistas sociais tão brilhante quanto o pai dele. David respondeu, do seu jeito áspero, mas não inamistoso: "Durante a minha carreira encontrei apenas três pessoas tão inteligentes quanto papai: Roman Jakobson, Lévi-Strauss e Erving!”

J.R.S.G. Para Franz Boas, Edward Sapir era "um dos pesquisadores mais brilhantes em linguística e antropologia do nosso país...". No entanto, as ideias antropológicas de Sapir não exerceram tanta influência na história da antropologia norte-americana. Não podemos dizer o mesmo sobre as suas obras linguísticas. Como você situaria a obra antropológica de Sapir no contexto da antropologia norte-americana? Como você explicaria o interesse recente nos seus trabalhos antropológicos?

R.H. Começo pela sua última pergunta; há uma razão prosaica para o interes se recente em Sapir: 1984 foi o centenário do seu nascimento e os seus descendentes (biológicos e intelectuais) aproveitaram a ocasião para organizar encontros acadêmicos e sessões dedicadas à sua obra e também para lançar o projeto ambicioso de publicar as suas obras completas.

Mas, é claro, há razões mais profundas: a posição intelectual de Sapir - seu foco no indivíduo dentro da cultura (Preston, 1966) e em uma teoria da cultura fundada em um profundo entendimento da epistemologia pressuposta por uma teoria estruturalista da linguagem, incrementado pela sua perspicácia etnográfica - estava de novo na moda em 1984. (Lembre-se e de que os antropólogos, mais do que os estudiosos na maioria das outras disciplinas, retornam aos seus ancestrais, considerando os trabalhos não apenas inspiradores, mas também úteis.)

A afirmação de que "as ideias antropológicas de Sapir não exerceram tanta influência na história da antropologia norte-americana", por sua vez, é questionável. Eu diria que o foco de Sapir no indivíduo dentro da cultura, em oposição ao indivíduo como um reflexo posterior à cultura, sempre foi uma posição minoritária, embora necessária, dentro da antropologia norte-americana. Na verdade, era estruturalmente necessária. Como Louis Dumont (1983) lembrou, no âmbito de uma ideologia moderna, o maior fardo da antropologia e da sociologia enquanto disciplinas é tornar a sociedadade visível a nativos 
que privilegiam "o indivíduo". Ao fazer isso, as ciências sociais deixam o indivíduo escapar, e o negam, o que, então, provoca uma reação, representada por Sapir à sua época, que tenta recuperar um lugar para o indivíduo enquanto ator dentro da cultura. Sapir não minimizou a importância da cultura (e da sociedade) na sua antropologia. Pelo contrário, o seu profundo entendimento da linguagem lhe deu instrumentos notáveis para falar sobre como a cultura funciona. Mas, talvez porque tenha estudado línguas indígenas norte-americanas, trabalhado com falantes nativos cujas "intuições" sobre a sua própria língua o deixaram cada vez mais impressionado e, talvez, porque também fosse poeta e músico, viu que o trabalho da cultura acontecia dentro e especialmente entre pessoas individuais. Estas ideias têm uma relevância duradoura, embora, como sugeri, entrem e saiam de moda.

Finalmente, gostaria de dizer que quando fui estudante de graduação na Universidade de Columbia entre 1968 e 1972, Sapir ainda estava "vivo", era um ancestral relembrado nos cursos sobre cultura e personalidade. Mas, àquela época, a antropologia de Boas estava em declínio, prestes a ser esquecida, antes de ser ressuscitada, sobretudo pelo trabalho histórico de George Stocking. Quando eu estava completando a minha tese, no final dos anos setenta, eu passara a considerar Sapir (Benjamin Lee Whorf, Ruth Benedict, e, sobretudo, Franz Boas) extremamente relevantes para a antropologia "pós-estruturalista" e "pós-moderna" (Handler, 1984). Claro, a ironia é que no mundo mais amplo dos estudos culturais e mesmo em grande parte da antropologia, os seguidores de Boas tinham sido esquecidos. Segundo a observação mordaz de Robert Brightman (1995), a nova antropologia se articulou com base em teóricos franceses, repetindo de várias formas o que os seguidores de Boas já tinham feito, sem ter nenhum conhecimento da sua contribuição.

J.R.S.G. Poderíamos afirmar que Sapir vê a cultura sobretudo enquanto linguista. Para ele, as culturas podem ser pensadas como linguagens. Mas, quando pensa sobre linguagem, quão próxima ou distante está das ideias de Saussure? Como o conceito de linguagem específico de Sapir reverbera no seu conceito de cultura?

R.H. Deixo a discussão sobre Saussure para os especialistas. É em geral consensual que um "estruturalismo americano" emerge na América do Norte por volta do mesmo período em que Saussure está formulando a sua abordagem na Europa; também se concorda que as duas "escolas" são historicamente independentes. Como afirmaram Dell Hymes e John Fought, "o fato é que Sapir, que completara a sua gramática do Takelma pouco antes de 20 de fevereiro de 1911 [...] não necessitou de uma publicação de 1916 [o Cours de linguistique générale, de Saussure] para estimulá-lo ao estudo sincrônico, analítico das línguas [...]. Por volta de 1916, Sapir, aliás, lançara as bases para o nosso conhecimento da estrutura de seis línguas [...]. O estudo sobre o Takelma é um uma das 
gramáticas mais elaboradas de uma língua que nunca tinha sido analisada ou escrita anteriormente, quase um milagre no seu tempo" (1981:15-16).

No que respeita à relação entre o conceito de linguagem e os conceitos de linguagem e cultura de Sapir, pode-se dizer que os dois são isomórficos. A linguagem "funciona" mediante oposições estruturais relevantes em todos os níveis, do som à gramática e à fala. O estabelecimento de padrões culturais funciona do mesmo modo. $\mathrm{Na}$ análise tanto da cultura quanto da linguagem, antropólogos e nativos descobrem, interpretam e produzem significados, com base em oposições, definições, conceitos, valores etc., concebidos arbitrariamente. A palavra "arbitrário" é um modo de dizer que os significados culturais jamais estão dados na natureza, são sempre produto da atividade humana em contextos históricos específicos. E como os padrões culturais são historicamente específicos, mudam ao longo do tempo.

J.R.S.G. Qual a importância das conexões pessoais e intelectuais de Sapir com o milieux do modernismo americano artístico e literário para se entender a sua antropologia? Sapir, de certo modo, é obcecado com a ideia de "forma". Como você descreveria a relevância das ideias estéticas de Sapir para o entendimento do seu conceito de cultura?

R.H. O modernismo é uma variante dentro de uma longa tradição de pensamento no Ocidente, a qual, seguindo Tocqueville e Dumont, entendemos como individualismo. Como o romantismo, que o precedeu, enquanto período histórico-literário, o modernismo, enquanto filosofia estética, enfocava a relação entre criatividade individual e forma cultural: "Tradição e talento individual", como indica o título de um ensaio de T. S. Eliot. O indivíduo - o artista, o criador, o gênio - está dado de antemão nesta abordagem, e ele (ou, às vezes, ela) ocupa, conceitualmente, um lugar precípuo. O artista é o herói cultural, e ainda que o modernismo possa reconhecer padrões sociais e culturais nas formas estéticas, a premissa é de que grandes indivíduos vão se erguer para além destas formas e, assim, transformá-las.

Sapir inicia o trabalho de análise estética a partir deste ponto. Enquanto antropólogo, está interessado, sobretudo, na apropriação individual criativa de formas culturais (e linguísticas) dadas. De um modo tipicamente modernista, descreve o artista como uma pessoa capaz de ter domínio sobre os recursos formais existentes na língua e na cultura e, então, "soltar-se" delas para criar uma nova arte, forjada a partir de elementos formais recém-criados (Sapir, 1924).

Contudo, Sapir difere da maioria dos críticos literários do seu tempo graças ao seu profundo conhecimento de línguas não-ocidentais. Sabia que a "grande tradição" ocidental é apenas uma possibilidade na história humana, e que outras línguas (aquelas dos índios norte-americanos, por exemplo) forneciam a seus falantes recursos formais igualmente ricos, a despeito do fato de os estudiosos ocidentais desprezarem estas línguas como "primitivas". Uma 
palavra que Sapir usava com frequência em seus escritos literários e linguísticos era "intuição" (e o verbo derivado "intuir"). Sapir argumentava que "falantes nativos" intuíam as estruturas formais da sua língua, ainda que não fossem capazes de descrevê-las conscientemente. Os artistas, portanto, são pessoas com intuições particularmente aguçadas das formas culturais, e a capacidade de manejá-las criativamente.

J.R.S.G. Para Sapir, as culturas, quando autênticas, são experiências de criatividade. Você vê alguma semelhança entre as ideias de Sapir sobre cultura e autenticidade e o conceito de cultura como "criatividade" de Roy Wagner, tal como ele o formula em seu famoso livro The invention of culture (publicado recentemente no Brasil)?

R.H. Temos que ser cuidadosos para não introduzir na leitura de Sapir ideias que pareçam semelhantes ou correlacionadas às de teóricos posteriores, como as de Roy Wagner. Não creio que Sapir tenha alcançado a ideia de Wagner de que o antropólogo de fato "inventa" a cultura na medida em que interage com as pessoas que estuda (pessoas que estão, é claro, ao mesmo tempo inventando um modo de incorporar o antropólogo em seu universo dotado de sentido, presumivelmente não nos termos do conceito ocidental de cultura). Mas Sapir chegou perto. No seu magnífico ensaio sobre "Cultural anthropology and psychiatry", Sapir (1932: 235-236) escreveu, "a assim chamada cultura de um grupo de seres humanos, como é tratada ordinariamente pelo antropólogo cultural, é essencialmente uma lista sistemática de padrões de comportamento socialmente herdados que podem ser ilustrados no comportamento de fato de todos ou da maioria dos indivíduos do grupo". Aqui demonstra-se que a cultura (como Lévi-Strauss argumentaria mais tarde) é um modelo construído pelo antropólogo. Há uma tensão entre o modelo e o que as pessoas realmente fazem ("o comportamento efetivo"), mas Sapir ainda inclui em sua discussão a ideia de "padrões" culturais "socialmente herdados". Não estou certo de que Wagner quisesse continuar preso a este conceito.

Sapir prossegue, então, afirmando que o "verdadeiro lócus" do processo cultural (do qual o antropólogo "abstrai" um modelo da cultura) reside "nas interações de indivíduos específicos". Demonstra que a cultura é um processo, uma atividade, não uma coisa. Esta abordagem faz de Sapir um predecessor potencial (como foi para mim) de teóricos do final do século XX que queriam "desconstruir" o conceito de cultura, que se tornara excessivamente estático.

J.R.S.G. Como Sapir se distingue intelectualmente do seu background boasiano? Em termos mais específicos, como você distinguiria a persona intelectual de Sapir de outros boasianos, como Ruth Benedict e Margareth Mead?

R.H. Como já observei antes, Sapir priorizava o indivíduo, as interações dos indivíduos, na sua abordagem teórica da cultura. O contraste com Benedict, e 
seu grande livro Patterns of culture (1934), é claro. O objetivo de Benedict era transmitir o conceito de cultura a um público amplo. Para isso, ela apresentava um retrato do indivíduo como determinado, ou mesmo superdeterminado pela cultura. Sapir vigorosamente discordava neste ponto (Handler, 1986), como já discordara em sua famosa resposta à afirmação de Kroeber sobre o "superorgânico" (Kroeber, 1917; Sapir, 1917).

No entanto, seria justo dizer que os boasianos eram uma "escola" (Stocking, 1974:17-18), um grupo de estudiosos cujas abordagens teóricas guardavam entre si uma semelhança de família. Todos os boasianos entendiam as culturas como historicamente produzidas, como um conjunto esteticamente padronizado de símbolos, valores e práticas - em suma, "formas de vida". Entendiam que a criatividade individual operava em tensão dialética com padrões culturais herdados. Como sugeri acima, enquanto uma teoria cuja questão fundamental se articulava em termos do "individual" vs. "o social" (ou, "o cultural"), a antropologia boasiana pode ser entendida como tipicamente moderna, e tipicamente modernista. No entanto, há espaço nas teorias modernistas para dar mais valor ao individual que ao social, e vice-versa.

J.R.S.G. O que você teria a dizer sobre as relações de Sapir com a vida cultural e intelectual alemã? Sapir tinha familiaridade com a cultura alemã. Você acha que autores alemães (como, por exemplo, Georg Simmel) tiveram algum papel na sua formação intelectual? Você acredita que a ideia alemã de Bildung tem alguma importância nas reflexões de Sapir sobre cultura e personalidade?

R.H. Em vez de pensar sobre a antropologia de Boas no contexto do individualismo moderno, podemos pensar sobre ela em termos do romatismo alemão e da epistemologoa neokantiana (Bunzl, 1996). Eu sempre me admirei por que mais pessoas não escreveram sobre parentesco intelectual, que se destaca entre as obras de Boas, Weber e Nietzsche - ou seja, por que não se dedicou mais atenção às várias tradições das ciências sociais do início do século XX que se originaram do neokantismo. Em todo caso, a questão aqui se torna história versus ciência, ou Geisteswissenschaften (ciências do espírito) versus Naturwissenschaften (ciências da natureza). Como Stocking (1974) mostrou, Boas imaginava a antropologia como uma ciência histórica, mas, deste modo, levava a sério a sua dimensão científica, incluindo a sua relação com as ciências físicas e da natureza. Os seus estudantes diferiam entre si na ênfase que conferiam à ciência histórica, centrada na interpretação cultural, ou à ciência natural, centrada na explicação causal.

No que diz respeito especificamente à sua pergunta, Sapir fez os seus estudos de graduação e mestrado em germanística na Universidade de Columbia, até um encontro apócrifo com Boas fazê-lo mudar para a antropologia (Mandelbaum, 1949: vii; ver Darnell, 1990: 9). A dissertação de mestrado de Sapir era dedicada à teoria de Herder sobre a origem da linguagem (Sapir, 1907). 
E, é claro, sua primeira língua foi yiddich. Portanto, Sapir estava profundamente arraigado à cultura alemã antes de encontrar Boas. Sob a orientação de Boas, aprenderia uma antropologia profundamente marcada pelas diversas tradições filosóficas alemãs que acabo de mencionar. Dívidas específicas, no entanto, são difíceis de identificar, embora durante a controvérsia com Kroeber em torno do conceito do superorgânico, Sapir declarou-se "um grande devedor" do filósofo Heinrich Rickert pela "penetrante análise da distinção fundamental entre ciência histórica e ciência da natureza" (1917: 447). Não sei dizer em que medida Sapir estava conscientemente influenciado pela ideia de Bildung ao elaborar as suas ideias sobre cultura e criatividade. No entanto, uma referência intelectual mais próxima seria Matthew Arnold (Handler, 1989).

J.R.S.G. Sapir é um dos principais autores que você enfoca no seu último livro Critics against culture. O que você poderia dizer sobre Sapir como um "observador da cultura de massa" ou como um "crítico contra a cultura"? Quão importante é, neste sentido, a posição adotada por Sapir para o entendimento da sua famosa oposição entre cultura "autêntica" e "espúria"? Você acredita que esta oposição seja útil para a análise antropológica das formas de vida cultural? Ou trata-se apenas de uma formulação ideológica modernista sobre a cultura?

R.H. Boas e seus estudantes eram "intelectuais públicos" que queriam chamar a atenção de um público amplo para o saber antropológico. Eram também participantes da cultura literária e artística do seu tempo; é notório que Sapir, Benedict e Mead escreveram e publicaram poesia, e Sapir também escreveu quantidade razoável de crítica literária (Darnell, 1990: 151-70; Handler, 1986). Sapir era mais atuante nestas áreas entre 1910 e o início dos anos vinte. Este foi um período no qual os intelectuais passaram de uma perspectiva otimista em relação às possibilidades de desenvolvimento cultural norte-americano para uma visão pessimista (especialmente depois que os horrores da Primeira Guerra Mundial ficaram evidentes) sobre o possível colapso da civilização.

Havia poetas americanos que Sapir admirava (como Emily Dickinson e Edwin Arlington Robinson), mas gradualmente ele se desencantou com o modernismo e a política de celebridades literárias. De modo semelhante, o seu entusiasmo anterior pelo herói-artista esmoreceu na medida em que a cultura comercial americana e seu culto do que poderíamos chamar de indivíduo ready-made, ou prefabricado, o desencorajou. Em "Culture, genuine and spurious", podemos perceber tanto a pespectiva otimista quanto a pessimista. Neste ensaio, Sapir condena o que considera "desajuste cultural" e "externalidade estéril" da vida na América do Norte (1924:414). Mesmo assim, acaba o ensaio com um tom otimista, ao prever o desenvolvimento vigoroso de culturas regionais, comunidades menores do que o Estado-nação no Canadá ou Estados Unidos, mas ricas o bastante em pessoas e recursos para alimentar a criatividade individual. 
Quanto à utilidade da autenticidade como um conceito para a análise da cultura, penso que podemos tomá-lo como um termo nativo, ou seja, como um termo fundador para o tipo de modernismo literário e antropológico que Sapir representa. Tendo em vista uma teoria da cultura baseada na dialética entre a sociedade e o indivíduo, faz sentido valorizar (a exemplo de Sapir) configurações sociais que tendem a contribuir para a liberdade humana. Mas os antropólogos podem reconhecer que "liberdade" é, em si mesma, um termo carregado de valor que adquiriu uma importância global nos discursos sobre os direitos humanos, por exemplo, mas que não é necessariamente útil para a análise cultural comparativa que busca transcender a dicotomia entre indivíduo e sociedade.

J.R.S.G. Atualmente, há um debate, ainda em curso, acerca das relações entre natureza e cultura, e muitos autores problematizam a distinção ontológica entre natureza e cultura. Como você descreveria a relevância das ideias antropológicas de Sapir para o debate contemporâneo sobre as relações entre "cultura" e "natureza"?

R.H. Com relação a esta questão, Sapir deve ser visto como um teórico formado pela distinção oiticentista entre ciências históricas e naturais, uma distinção que pressupõe a dicotomia natureza-cultura. A partir de um profundo entendimento sobre como a linguagem estrutura a nossa relação com o mundo (com a "natureza," se você quiser), Sapir articulou uma epistemologia neokantiana na qual categorias culturais (e gramaticais) são fudamentais para todo pensamento e prática humanos. Podemos terminar esta entrevista com uma das declarações mais adoráveis de Sapir sobre a primazia de categorias linguístico-culturais para a experiência humana: "Agora os fantasiosos universos de significados autocontidos são os mais refinados e nobres substitutos que jamais poderemos inventar para aquele preciso e amoroso entendimento das fissuras e dos recantos do real, que para sempre nos será negado" (Sapir, 1939: 239). Sapir reconheceu que a "cultura" era, em si mesma, um construto cultural e podemos presumir que fosse entender "natureza" da mesma forma. Mas não creio que reconhecesse a necessidade de superar a posição clássica idealista segundo a qual mente, linguagem e cultura devem ser entendidas como algo distinto da natureza. 
José Reginaldo Santos Gonçalves é Ph.D em Antropologia Cultural pela Universidade de Virgínia, professor do Programa de PósGraduação em Sociologia e Antropologia (PPGSA) e do Departamento de Antropologia Cultural da Universidade Federal do Rio de Janeiro (UFRJ), e pesquisador 1 do Conselho Nacional de Desenvolvimento Científico e Tecnológico (CNPq). Atualmente desenvolve projetos de pesquisa sobre os seguintes temas: patrimônios culturais e discursos arquitetônicos, discursos da memória, teorias da cultura. É autor de A retórica da perda: os discursos do patrimônio cultural no Brasil (2a ed., 2002) e organizador de A experiência etnográfica: antropologia e literatura no século XX (textos de James Clifford) (2002). Seu último livro foi Antropologia dos objetos: coleções, museus e patrimônios (2007). 


\section{REFERÊNCIAS BIBLIOGRÁFICAS}

Benedict, Ruth. Patterns of culture. Boston: Houghton Mifflin,1934.

Brightman, Robert. Forget culture: Replacement, transcendence, relexification. Cultural Anthropology, 1995,10/4, p. 509-546.

Bunzl, Matti. Franz Boas and the Humboldtian tradition. History of Anthropology, 1996, 8, p. 17-78.

Darnell, Regna. Edward Sapir: Linguist, anthropologist, humanist. Berkeley: University of California Press, 1990.

Dumont, Louis. Essais sur l'individualisme. Paris: Éditions du Seuil, 1983.

Eliot, T. S. Tradition and the individual talent. In:

The sacred wood. Londres: Methuen \& Co.

Goffman, Erving. Stigma: Notes on the management of spoiled identity. Englewood Cliffs: Prentice Hall, 1963.

Handler, Richard. A cultural account of kinship and marriage in Jane Austen's novels. Tese de Mestrado, Departamento de Antropologia, University of Chicago, 1976 (não publicada).

The dainty and the hungry man: Literature and anthropology in the work of Edward Sapir. History of Anthropology, 2005, 1, p. 208-31. (Republicado em Handler, 2005: 49-72).

On sociocultural discontinuity: Nationalism and cultural objectification in Quebec. Current Anthropology, 1984, 25/1, p. 55-71.

Vigorous male and aspiring female: Poetry, personality, and culture in Edward Sapir and Ruth Benedict. History of Anthropology, 1986, 4, p. 127-155. (Republicado em Handler, 2005: 96-122)

Antiromantic romanticism: Sapir's critique of American individualism. Anthropological Quarterly, 1989, 62/1, p. 1-13. (Republicado em Handler, 2005: 73-95).

Critics against culture: Anthropological observers of mass society. Madison: University of Wisconsin Press, 2005.

Erving Goffman and the gestural dynamics of modern selfhood. In: Braddick, Michael J. (org.). The politics of gesture: 
Historical perspectives. (Suplemento de Past and Present), p. 280-300.

What's up, doctor Goffman? Tell us where the action is. Journal of the Royal Anthropological Society, 2012, 18, p. 179-190.

\& Segal, Daniel. Jane Austen and the fiction of culture: An essay on the narration of social realities. Tucson: University of Arizona Press, 1990. (Republicado pela Rowman \& Littlefield, 1999).

Hymes, Dell \& Fought, John. American structuralism. The Hague: Mouton, 1981.

Kroeber, Alfred. The superorganic. American Anthropologist, 1917, 19/2, p. 163-213.

Mandelbaum, David. Editor's Introduction. In: Selected writings of Edward Sapir. Berkeley: University of California Press, p. v-xii.

Preston, Richard. Edward Sapir's anthropology: Style, structure and method. American Anthropologist, 1966, 68, p. 11051127.

Sapir, Edward. Herder's Ursprung der Sprache. Modern Philology, 1907, 5, p. 109-142.

Do we need a 'superorganic'?. American Anthropologist, 1917, 19, p. 441-447.

Culture, genuine and spurious. American Journal of Sociology, 1924, 29, p. 401-429.

. Cultural anthropology and psychiatry. Journal of Abnormal and Social Psychology, 1932, 27, p. 229-242. Psychiatric and cultural pitfalls in the business of getting a living. Mental Health, 1939, 9, p. 237-244.

Stocking Jr., George W. The basic assumptions of Boasian anthropology. In:____ (org.). The shaping of American anthropology, 1883-1911: A Franz Boas reader. Nova York: Basic Books, 1974, p. 1-20.

Ideas and institutions in American anthropology: Toward a history of the interwar period. In: (org.). Selected papers from the American Anthropologist, 1921-1945. Washington, DC: American Anthropological Association, 1976, p. 1-44. 
Palavras-chave: Resumo:

Edward Sapir; Richard

Handler; Cultura e

Nesta entrevista, Richard Handler, um dos editores obra do linguista e antropólogo Edward Sapir, trata da linguagem; Antropologia importância dessa obra e da sua influência sobre seu norte-americana; trabalho enquanto antropólogo cultural, situando as Antropologia e modernismo. ideias de Sapir no contexto da tradição antropológica norte-americana e do modernismo artístico e literário das primeiras décadas do século XX nos Estados Unidos. Handler assinala a permanência dessas ideias na história da antropologia norte-americana e sua atualidade nos debates antropológicos.

\section{Keywords:}

Edward Sapir; Richard Handler; Culture and Language; North American Anthropology;

Anthtopology and modernism.

\begin{abstract}
:
In this interview, Richard Handler, one of the editors of the works of the linguist and anthropologist Edward Sapir, focuses on the importance of this work and its influence on his own work as a cultural anthropologist, and situates Sapir's ideas in the context of the North American anthropological tradition and the American artistic and literary modernism at the first decades of the $20^{\text {th }}$ century. Handler stresses the permanence of these ideas in the history of American Anthropology and their relevance for the present anthropological discussions.
\end{abstract}

